\title{
blzINVENTÁRIO DE ARBORIZAÇÃO DE 12 PRAÇAS NO MUNICÍPIO DE ITUVERAVA-SP
}

\author{
MARIANO, Renato de Souza ${ }^{1}$ \\ OLIVEIRA, Renato Luis Nunes ${ }^{2}$ \\ PEREIRA, Marcio $^{3}$
}

\begin{abstract}
RESUMO: Este trabalho teve como objetivo fazer o inventário arbóreo, quantificando e qualificando 12 praças na cidade de Ituverava. No presente estudo, utilizou-se o mapa do município de Ituverava, para a caracterização e identificação das áreas de estudo, sendo usado o método censo. Outras informações, consideradas importantes, foram catalogadas: localização, diversidade de espécies e número total de exemplares arbóreos. O total de indivíduos foi de 435. Em 3 praças, 52\% foram da espécie Michelia champaca; 2 praças têm 100\% de Thuja orientalis jovens; 2 praças têm 29\% de Roystonea oleraceae; 1 praça tem 100\% de Syagrus romanzoffiana ; em 3 praças, 23,5\% das árvores estavam com podas drásticas. Das 35 espécies encontradas, 16 apresentaram uma freqüência menor que 1\%, e 18 espécies são exóticas e 17 nativas. Concluiu-se que o maior problema encontrado foram as podas feitas sem critério técnico, e que existem praças com 1 única espécie.
\end{abstract}

Palavras-chave: Arborização. Censo. Praça.

\section{INVENTORY OF ARBORIZAÇÃO OF 12 SQUARES IN TOWN OF ITUVERAVA-SP}

SUMMARY: This study aimed to make the trees inventory quantifying and qualifying 12 squares in Ituverava. In the present study, it was utilized a map of the municipality of Ituverava, for characterization and identification of the areas in study, and the method used was census. Other informations, considered important, were cataloged: location, diversity of species and total number of copies "arbóreos". The individual total was 435 . On 3 squares, 52\% were of the kind Michelia champaca, 2 squares have $100 \%$ of young Thuja orientalis, 2 squares have $29 \%$ of Roystonea oleraceae, 1 square is $100 \%$ of Syagrus romanzoffiana; at 3 squares, $23.5 \%$ of the trees were with diastic pruning from 35 species found, 16 had a less frequency than $1 \%, 18$ species are exotic and 17 native. It was concluded that the main problem found was the pruning made without technical criterion and that there are squares with 1 single species.

Keywords: Arborization. Census. Square.

\footnotetext{
${ }^{1}$ Ciências Biológicas- Licenciatura - FFCL / Fundação Educacional de Ituverava.

2 Ciências Biológicas- Licenciatura - FFCL / Fundação Educacional de Ituverava.

3 Doutor em Recursos Florestais. Diretor/Prof. da Faculdade “Dr. Francisco Maeda”. Fundação Educacional de Ituverava.marciopereira@feituverava.com.br
} 


\title{
INTRODUÇÃO
}

A arborização urbana compõe um dos mais importantes elementos do ecossistema nas cidades e, por todo benefício que traz, deveria ser uma preocupação permanente em todo planejamento urbano. (VERAS, 1986 apud HARDER, 2002)

O crescimento desordenado da maioria das cidades brasileiras e a ocupação irregular do solo têm dificultado a execução de um planejamento adequado que integre a área construída com a vegetada, sejam estas naturais ou artificiais, prejudicando a qualidade de vida. (BIANCHI; GRAZIANO, 1992; DETZEL, 1992 apud HARDER, 2002)

A qualidade de vida de uma população que mora em uma cidade pode ser medida pela relação existente entre o número de árvores plantadas em ruas, praças e parques e o número de habitantes que nela vivem. As áreas livres são como campos de pesquisa: nelas, pode-se passear, fazer piqueniques ou praticar esportes. Pode-se, ainda, voltar à natureza, às origens das quais todos viemos e ainda não escapamos. O sistema de áreas verdes poderia interligar este arcabouço de espaços vazios ao redor das cidades às áreas centrais. (ECKBO, 1981)

\begin{abstract}
A qualidade de vida trata-se de conceito estático, enquanto sua aplicação ao homem, no dia-a-dia, é dinâmica e sofre influencia direta do avanço científico. Assim, os que outrora se podia entender como condições satisfatórias, hoje não se podem aceitar o mesmo titulo, porque a ciência possibilitou ao homem utilizar novos recursos que lhe podem proporcionar melhores condições de vida. Enquanto estática a conceituação, dinâmica é sua interpretação. Todas as condutas e atividades devem ser adequadas às necessidades do homem. Mas a dignidade humana "Não pode ser referida tão-somente ao indivíduo isolado, mas ter em conta a dimensão social dos seres humanos”. (MARQUES, 2005 apud BAEZ, 2006)
\end{abstract}

Relacionando as praças como áreas verdes, pode-se dizer que sua participação na qualidade de vida é muito grande, principalmente se ela for bem planejada, ou seja, bem iluminada, com bancos, banheiros, atividades comunitárias, em geral arborizada adequadamente, com todas suas podas adequadas desde as podas de educação, manutenção até as de seguranças geral. (HARDER, 2002)

Podas de Educação: poda dos galhos deve ser realizada o mais cedo possível, para evitar cicatrizes muito grandes, desnecessárias. A poda de formação na fase jovem sempre é uma mutilação, devendo ser executada com cuidado. O arboricultor deve ter em mente o modelo arquitetônico da espécie, considerando portanto o futuro desenvolvimento da copa no espaço em que a árvore está estabelecida. Galhos baixos 
que dificultarão a passagem de pedestres e veículos deverão ser eliminados precocemente. Galhos que cruzarão a copa ou com inserção defeituosa deverão igualmente ser eliminados antes que os cortes se tornem muito difíceis. $\mathrm{O}$ atrito de dois galhos provocará lesões enfraquecendo o lenho destes. Podas de Manutenção: Na poda de manutenção são eliminados basicamente galhos senis ou secos, que perderam sua função na copa da árvore. Estes galhos podem em algumas circunstâncias ter dimensões consideráveis, tornando o trabalho mais difícil do que na poda de formação. Na execução desta poda deve ser dada especial atenção à morfologia da base do galho. Podas de Segurança: Esta poda tecnicamente é semelhante à poda de manutenção, com a diferença de ser praticada em galhos normalmente vitais ou não preparados pela árvore para o corte. A alternativa para esta eventualidade, é o corte em etapas. Na primeira poda, o galho é cortado a uma distância de 50 a $100 \mathrm{~cm}$ do tronco. O galho assim debilidatado provocará a ativação dos mecanismos de defesa. Após um ou mais períodos vegetativos, procede-se à segunda poda, agora junto ao tronco, concluindo a operação de remoção do galho. (SEITZ, 1996)

Para conhecer a arborização é necessário fazer um inventário que tem como objetivo conhecer o patrimônio arbustivo de uma localidade. O tipo de inventário utilizado deverá ser de acordo com os objetivos especificamente definidos. (ROCHA; LELLES; OLIVEIRA NETO, 2004)

[...] os inventários podem ser por amostragem ou inventário total. Este último é mais direcionado para locais onde a freqüência da arborização é muito heterogênea como nos jardins, vias públicas ou bairros, ou em cidades de pequeno porte, conforme utilizado. (MILANO, 1994 apud ROCHA; LELLES; OLIVEIRA NETO, 2004).

Este trabalho teve como objetivo fazer o inventário arbóreo, quantificando e qualificando 12 praças dentro do município de Ituverava-SP.

\section{CONCEITOS}

Áreas verdes são diversos tipos de espaços abertos que têm que ser acessíveis, abertos, estar relacionados com as atividades humanas. Ligadas à saúde, à recreação ativa e passiva. (DEMATTÊ, 1997 apud HARDER, 2002)

Espaços livres são espaços abertos, reservados à área não construída, não destinada às grandes infra-estruturas. (LAPOIX, 1979 apud HARDER, 2002)

Arborização urbana define-se como conjunto de áreas públicas ou privadas com coberturas arbóreas naturais ou cultivadas que uma cidade apresenta. (GREY; DENEKE, 1978 apud HARDER, 2002) 
Praças são espaços abertos ao público que tem como objetivo incentivar o lazer e atividades comunitárias e, podem ser praças secas, onde não há vegetação, ou jardins, onde há vegetação (DEMATTÊ, 1997 apud HARDER, 2002).

Benefícios da arborização urbana são: benefícios psicológicos: parques, bosques, praças e outras áreas verdes possibilitam a recreação e lazer das pessoas, principalmente aquelas com baixa renda. Por sua relação com o estado de lazer e aproximação com a vegetação, desempenham um papel positivo no psicológico. Benefícios ecológicos: aumento da diversidade e quantidade da fauna, melhora do solo urbano, estabilidade microclimática, por causa das temperaturas mais baixas e da umidade, diminuição da poluição atmosférica, por meio da fotossíntese, melhoria ciclo hidrológico, melhoria nas condições de conforto acústico. (HARDER, 2002)

Benefícios econômicos: a vegetação, pela sua contribuição na qualificação ambiental e paisagística de imóveis, proporciona a eles uma valorização. (SANCHOTENE, 1994 apud HARDER, 2002).

A arborização será tanto mais reconhecida quanto maior for a percepção dos efeitos de melhorias para cidade. (DETZEL, 1992 apud HARDER, 2002)

Benefícios estéticos: a maioria das pessoas acha a estética mais benéfica em virtude da aparência das árvores e, também, através da camuflagem que, muitas vezes, se consegue com as árvores escondendo as friezas das construções. (MELLO FILHO, 1985; DETZEL 1990 apud HARDER 2002).

\section{MATERIAL E MÉTODO}

\subsection{COLETA DE DADOS}

O presente estudo foi desenvolvido no período de janeiro a junho de 2007. Para fazer o levantamento arbóreo de cada praça, foi usado o método censo, ou seja, uma contagem dos indivíduos. Em decorrência do baixo número de indivíduos arbóreos encontrados, as praças foram escolhidas aleatoriamente, sendo analisado o numero total de indivíduos de cada praça, procedência, ou seja, nativo ou exótico, indivíduos com podas ou não. 


\subsection{CARACTERIZAÇÃO DA ÁREA DE ESTUDO}

As doze praças estão distribuídas pelos seguintes bairros: COHAB, Vila São Sebastião, Vila Industrial, Vila Galize, Jardim Vale do Carmo, na cidade de Ituverava, cuja localização, no mapa, está ao nordeste do estado de São Paulo, no planalto ocidental Paulista, contando, atualmente, com 38.563 mil habitantes, distribuídos numa área de 698 km² (IBGE, 2005); situada a 631m de altitude, nas coordenadas geográficas: latitude sul - 20²0'30’’ e longitude oeste 47 47’30’'(PEREIRA; BARRACHI, 1997).

As Praças Nestor Alves Ferreira, Henrique Soares de Oliveira, João Ataíde de Souza, Prof. a Maria Inácia Coelho e Ida Migliori Coimbra estão localizadas na COHAB; as praças José Aparecido Fernandes, João Paulo II e Bispo Oliveira estão na Vila Galize; a Praça Flavio Cavalari está localizada no jardim Vale do Carmo; a José Costa Junior e a Orlando Teodoro da Silva na Vila Industrial, e a praça dos Maçons está localizada na Vila São Sebastião. (figura 1)

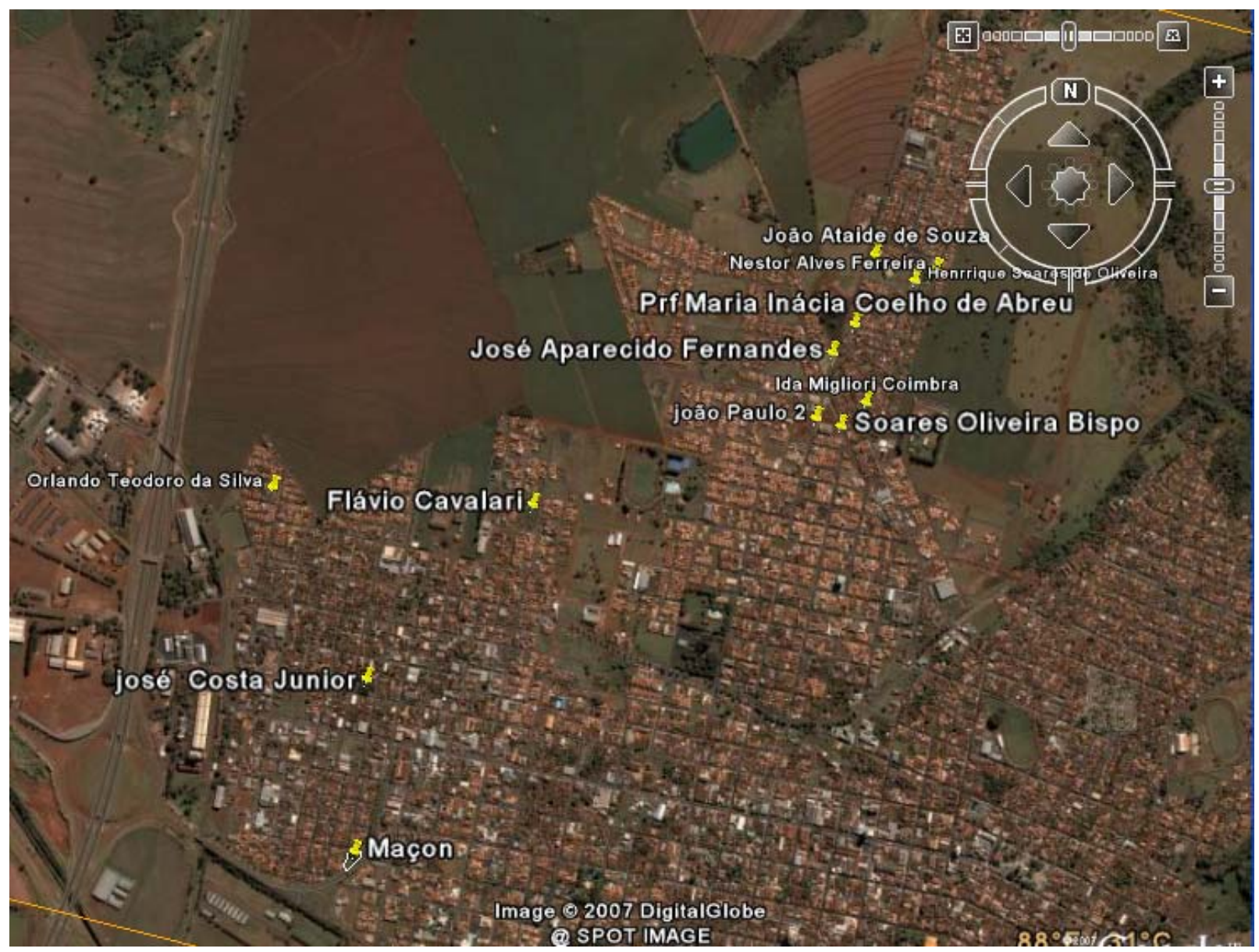

Figura 1: Mapa da cidade de Ituverava com as respectivas praças. 


\section{RESULTADO E DISCUSSÃO}

Na tabela 1, é apresentado o total de indíviduos, 435, divididos em 35 espécies identificadas e mais 13 indivíduos não identificados.

Tabela 1: Listagem das espécies amostradas com seus respectivos nomes científicos número de indivíduos e origem.

\begin{tabular}{|c|c|c|c|}
\hline Espécies Arbóreas & Nome Científico & 1 & 2 \\
\hline Árvore do dinheiro & Dillenia indica & 19 & $\mathrm{E}$ \\
\hline Ipê roxo & Tabebuia avellanedae & 45 & $\mathrm{~N}$ \\
\hline Chorão & Salix alba & 1 & $\mathrm{~N}$ \\
\hline Palmeira imperial & Roystonea oleraceae & 38 & $\mathrm{E}$ \\
\hline Mangueira & Mangifera indica & 0 & $\mathrm{E}$ \\
\hline Figueira & Ficus spp & & $\mathrm{N}$ \\
\hline Castanheira & Pachira aquatica & & $\mathrm{N}$ \\
\hline Magnólia & Michelia champaca & 88 & $\mathrm{E}$ \\
\hline Oiti & Licania tomentosa & 24 & $\mathrm{~N}$ \\
\hline Pau brasil & Caesalpinia echinata & 1 & $\mathrm{~N}$ \\
\hline Ipê de jardim & Tecoma stans & 2 & $\mathrm{E}$ \\
\hline Palmeira rabo de peixe & Caryota urens & 1 & $\mathrm{E}$ \\
\hline Angico & Anadenanthera spp & 1 & $\mathrm{~N}$ \\
\hline Limoeiro & Citrus spp & 1 & $\mathrm{E}$ \\
\hline Merinduva & Lafoensia glyptocarpa & 1 & $\mathrm{~N}$ \\
\hline Bálsamo & Miroxylon peruiferum & 4 & $\mathrm{~N}$ \\
\hline Sibipiruna & Caesalpinia peltophoroides & 10 & $\mathrm{~N}$ \\
\hline Palmeira jerivá & Syagrus romanzoffiana & 26 & $\mathrm{E}$ \\
\hline Jombolão & Syzygium cumini & 1 & $\mathrm{E}$ \\
\hline algodão & Hibiscus tiliaceus & 1 & $\mathrm{E}$ \\
\hline Abacate & Hyeronima alchorneoides & 1 & $\mathrm{~N}$ \\
\hline Pata de vaca & Bauhinia variegata & 4 & $\mathrm{E}$ \\
\hline Resedá rosa & Lagerstroemia indica & 12 & $\mathrm{E}$ \\
\hline Tangerina & Citrus reticulata & 1 & $\mathrm{~N}$ \\
\hline Escovinha de garrafa & Callistemon spp & 1 & $\mathrm{E}$ \\
\hline Paineira & Chorisia speciosa & 1 & $\mathrm{~N}$ \\
\hline Amendoim & 'Pterogyne nitens & 1 & $\mathrm{~N}$ \\
\hline Jacarandá minas & Jacaranda cuspidifolia & 1 & $\mathrm{~N}$ \\
\hline Grevilha & Grevillea robusta & 1 & $\mathrm{E}$ \\
\hline Mamica de porca & Zanthoxylun riedelianum & 1 & $\mathrm{~N}$ \\
\hline Espirradeira & Nerium oleander & 3 & $\mathrm{E}$ \\
\hline Palmeira arecá & Dypsis lutescens & 1 & $\mathrm{E}$ \\
\hline Tuias & Thuja orientalis & 94 & $\mathrm{E}$ \\
\hline Ipê Amarelo & Tabebuia Alba & 4 & $\mathrm{~N}$ \\
\hline \multicolumn{2}{|c|}{ Indivíduos não identificados } & \multicolumn{2}{|c|}{13} \\
\hline
\end{tabular}


*1 = Quantidade total de cada espécie

2 = Origens, nativa $(\mathrm{N})$ ou exótica $(\mathrm{E})$

Em relação à origem, foram encontrados as 18 espécies exóticas, ou seja, endêmicas de outros países e 17 nativas endêmicas de nosso país.(figura 2)

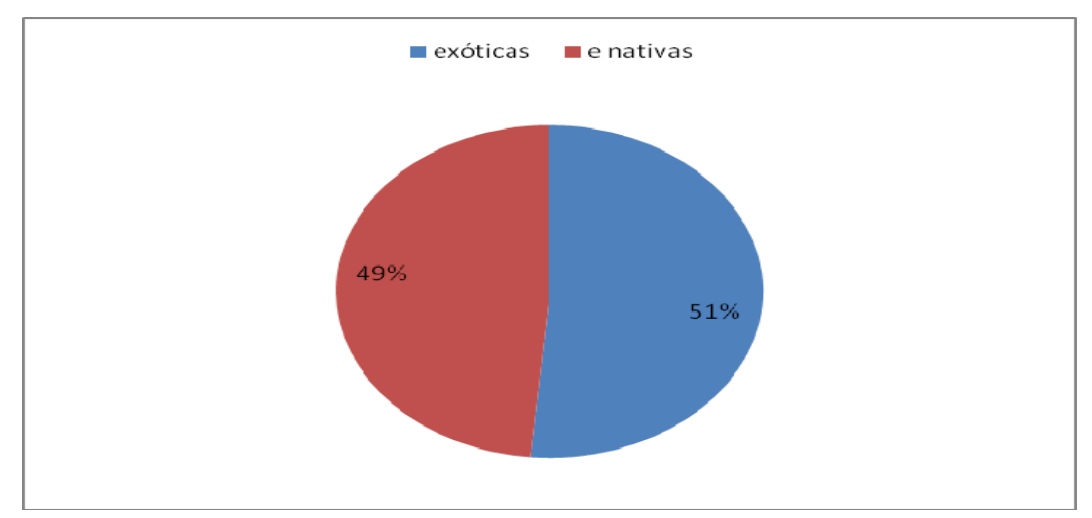

Figura 2: Total de indivíduos exóticos e nativos em todas as praças.

Na Praça José Aparecido Fernandes, localizada na Vila Galize, foram encontrados 71 exemplares arbóreos divididos em 8 espécies, sendo que as espécies que prevaleceram são a Roystonea oleraceae em primeiro com 30\%, a Dillenia indica com 27\% e o Tabebuia avellanedae com $25 \%$ respectivamente. (figura 3 )

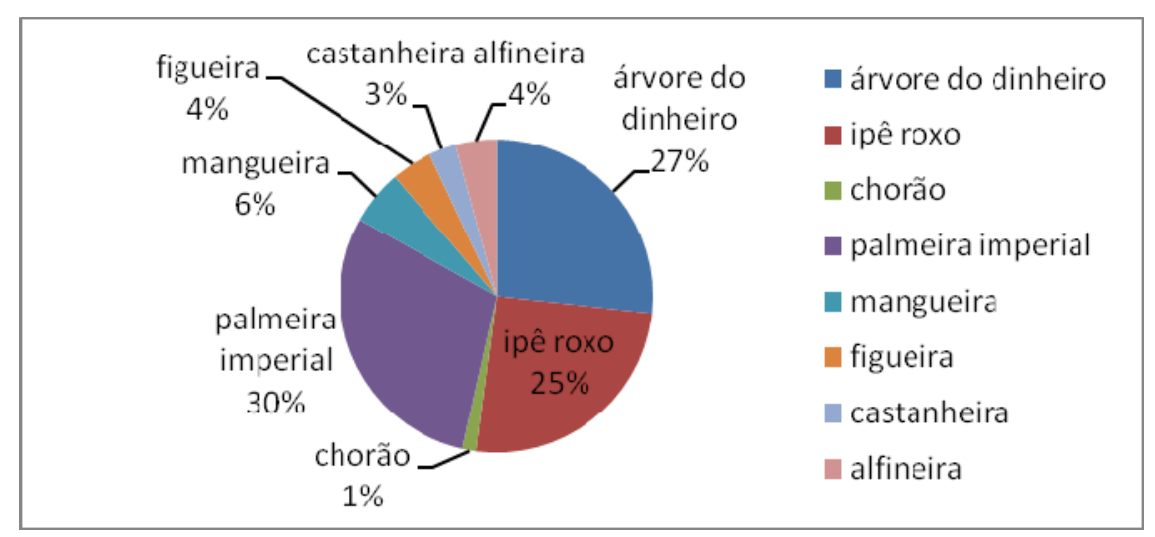

Figura 3: Espécies presentes na Praça José Aparecido Fernandes.

Na Praça Nestor Alves Ferreira, localizada no Bairro COHAB, foram encontrados 48 indivíduos arbóreos divididos em 10 espécies, sendo as espécies que mais prevaleceram, com $38 \%$, a Michelia champaca, e 21\%, Licania tomentosa. (figura 4) 


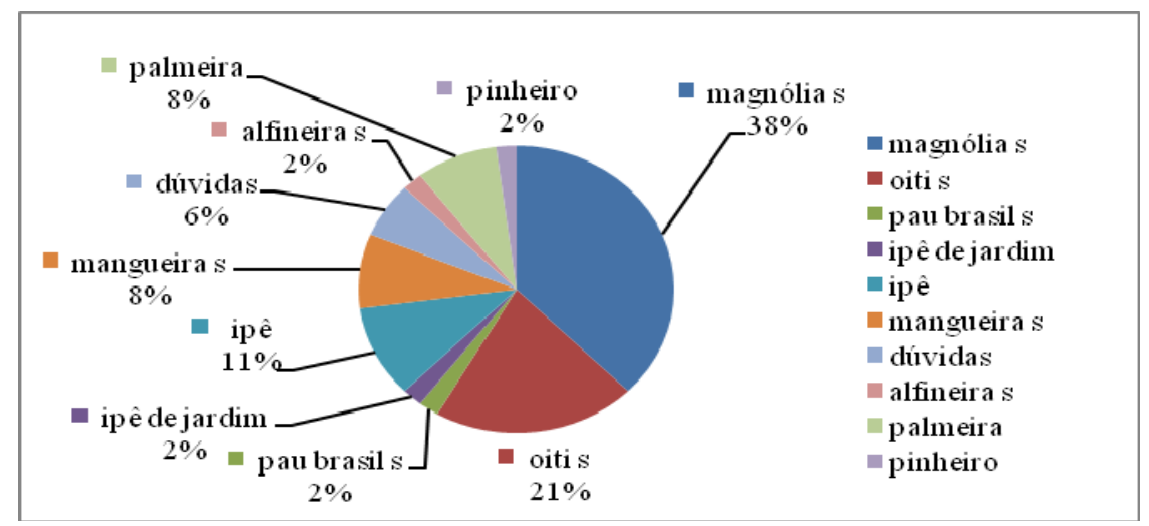

Figura 4: Espécies presentes na Praça Nestor Alves Ferreira.

Na Praça Maria Inácia Coelho, localizada também no bairro COHAB, foram encontrados 6 indivíduos e todos de diferentes espécies. (figura 5)

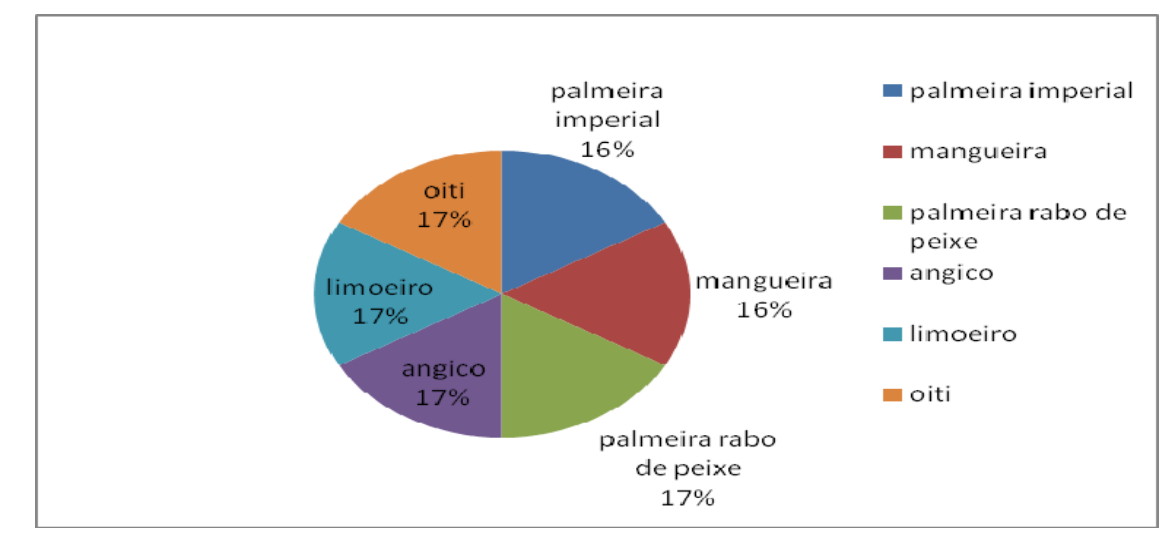

Figura 5: Espécies presentes na Praça Maria Inácia Coelho.

Pode-se observar que, na Praça Ida Migliori Coimbra, localizada no bairro COHAB, o total de indivíduos foi de 40, e as espécies que prevaleceram são a Roystonea oleraceae com 35\%, seguida da Michelia champaca, com 20\% e Licania tomentosa, com 13\%.( figura 6) 


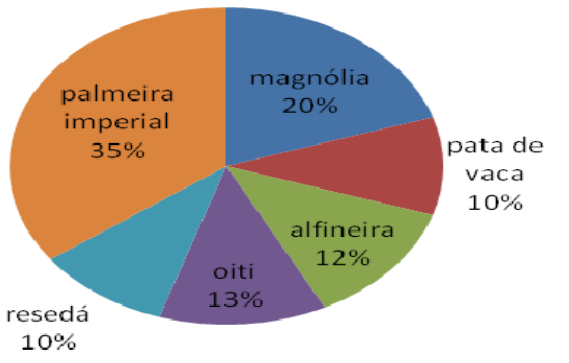

magnólia

- pata de vaca

alfineira

oiti

- resedá

Ealmeira imperial

Figura 6: Espécies presentes na Praça Ida Migliori Coimbra - Cohab.

Na praça Henrique Soares Oliveira, localizada no bairro COHAB, foram encontrados 13 indivíduos, distribuidos em 5 espécies, prevalecendo a Lagerstroemia indica com 61\%; Roystonea oleraceae com 15\% e o restante Citrus reticulata 8\%, Callistemon spp 8\% e outra sem identificação 8\%. ( figura 7)

Na praça João Ataíde, localizada no Bairro COHAB, foram encontrados 25 indivíduos, prevalecendo a Tabebuia avellanedae, com 84\%. (figura 8)

Localizada no bairro Jardim Vale do Carmo, a Praça Flávio Cavalari tem um total de 81 indivíduos arbóreos, sendo que as espécies que predominam são: a Michelia champaca com 77\%; Tabebuia alba com 5 \%, e, depois, a Syagrus romanzoffiana com 4\%. ( figura 9)

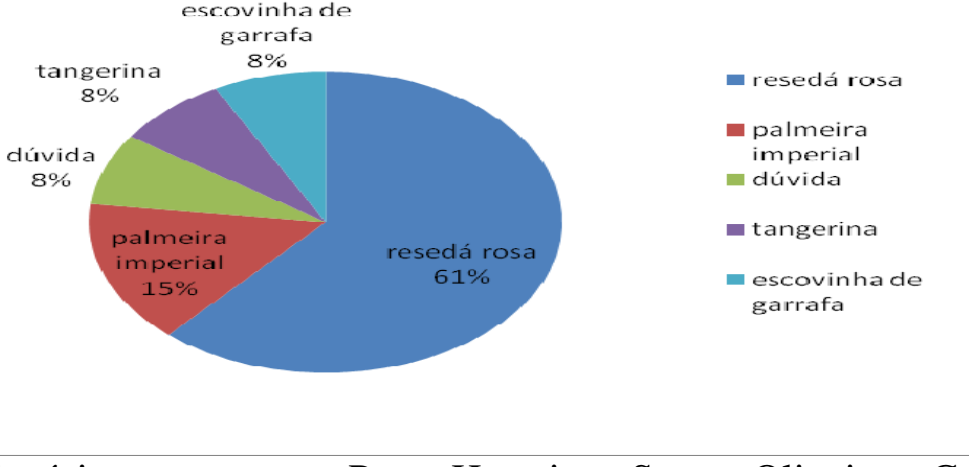

Figura 7: Espécies presentes na Praça Henrrique Soares Oliveira - Cohab. 


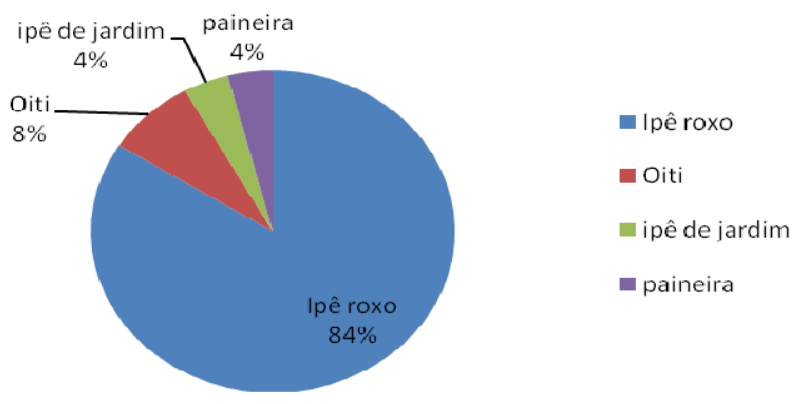

Figura 8: Espécies presentes na Praça Ataide Cohab.

Localizada na Vila São Sebastião, a praça Do maçon tem, ao todo, 20 indivíduos arbóreos, sendo as espécies predominantes a Pachira aquatica com 30\%; Licania tomentosa com 25\% e a Caesalpinia peltophoroides com 20\%. (figura 10)

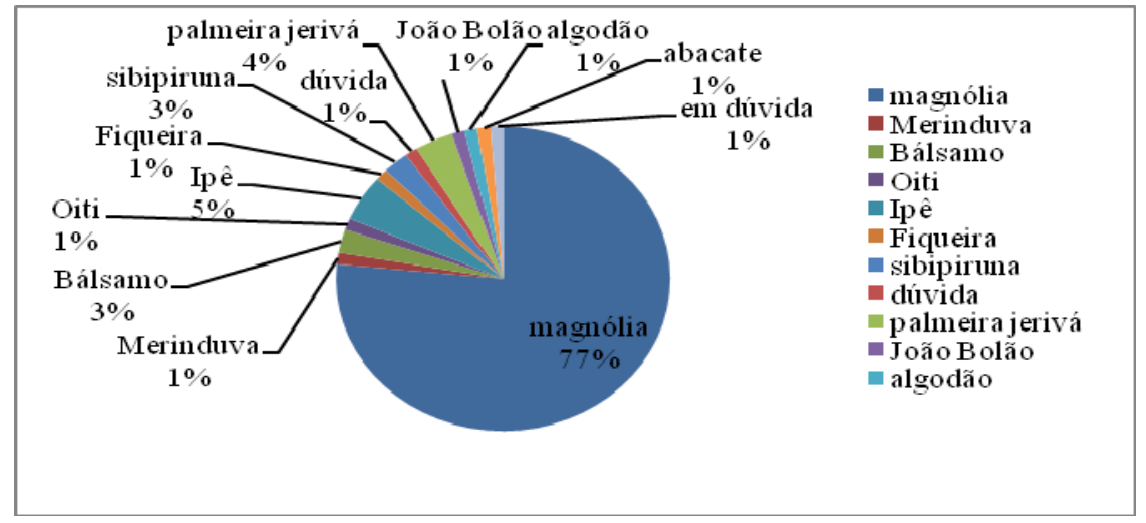

Figura 9: Espécies presentes na Praça Flávio Cavalari.

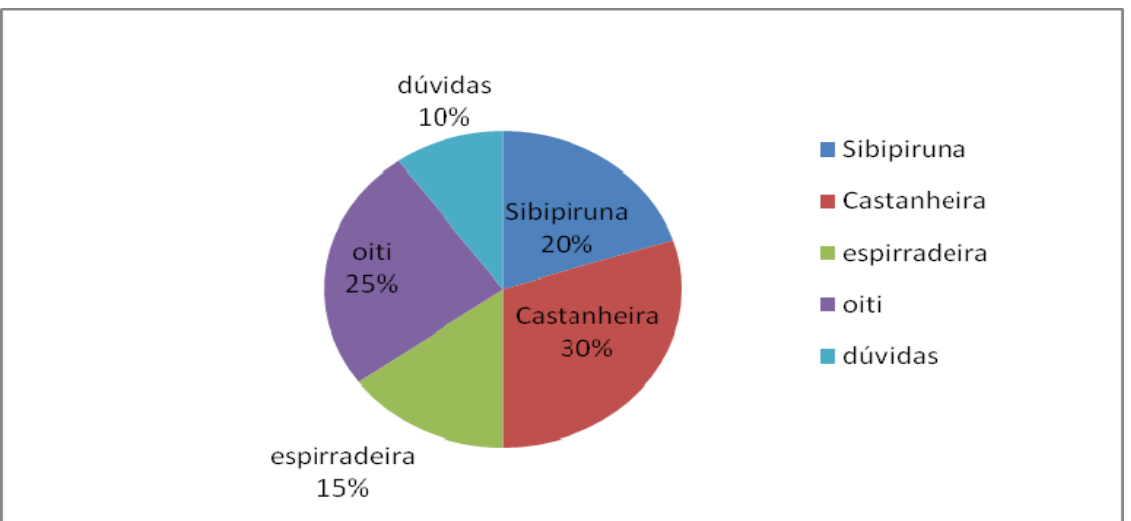

Figura 10: Espécies presentes na Praça Maçon - Parque do Trevo.

Na praça Orlando Teodoro da Silva, localizada na Vila Industrial, foram encontrados 23 
Indivíduos, predominando a espécie Syagrus romanzoffiana, com 100 \%.(figura 11)

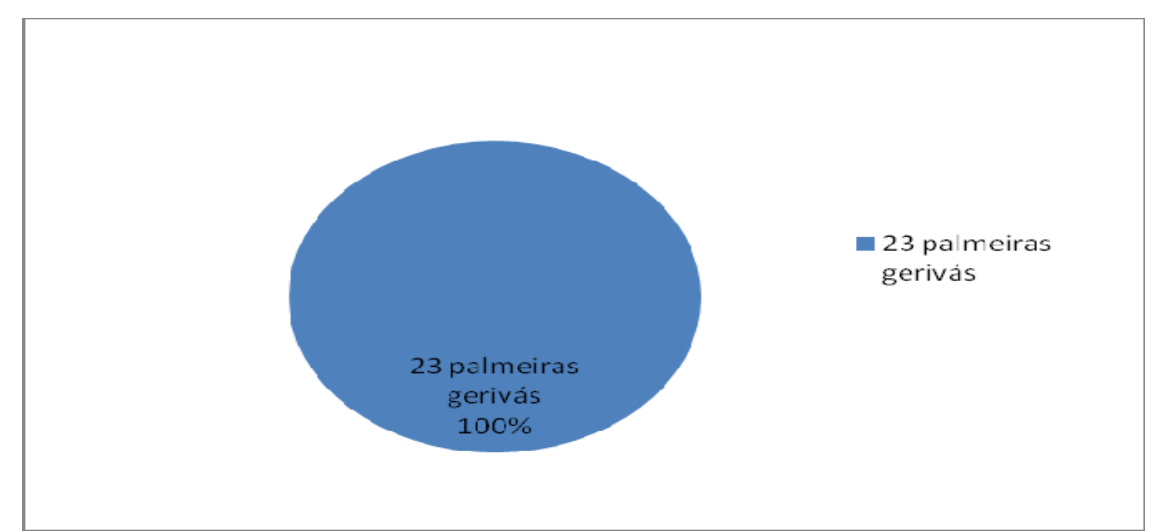

Figura 11: Espécie presente na Praça Orlando Teodoro da Silva.

Na praça Soares Oliveira, localizada no Bairro Vila Galize, foram encontrados 51 indivíduos com predominância da espécie Thuja orientalis com 100\%. (figura 12)

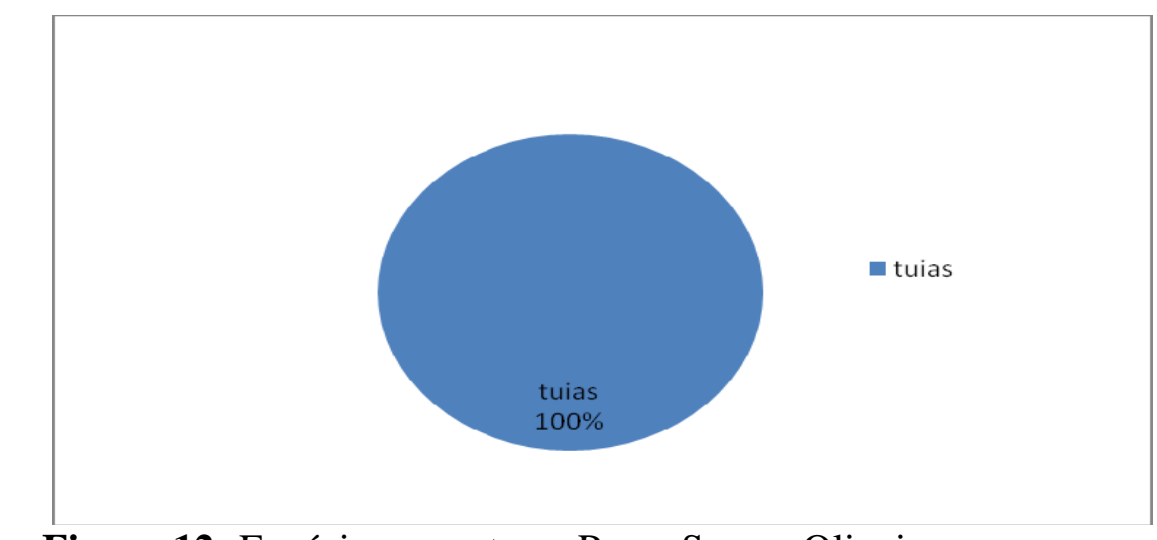

Figura 12: Espécie presente na Praça Soares Oliveira.

Na praça João Paulo II tambem na Vila Galize, há 42 individuos, e, somente, tuias.(figura 13) 


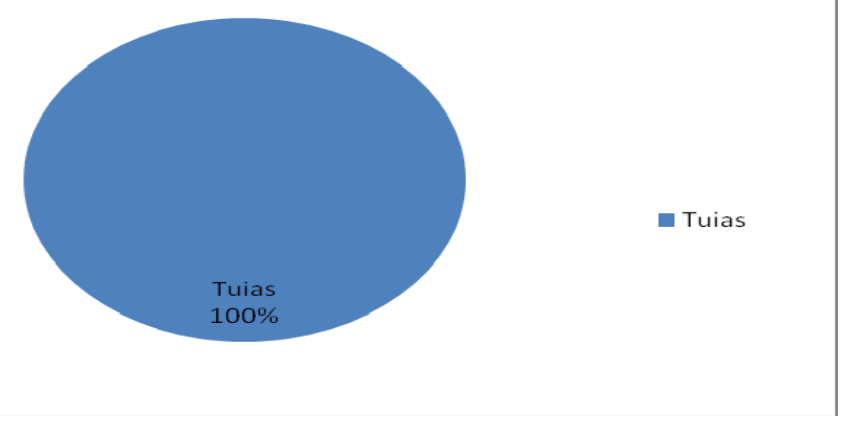

Figura 13: Espécie presente na Praça João Paulo II

A praça José Costa Junior, localizada na Vila Industrial, possui, ao todo, 15 indíviduos e a espécie que está predominando é a Caesalpinia peltophoroides, com 27\% do total.( figura 14)

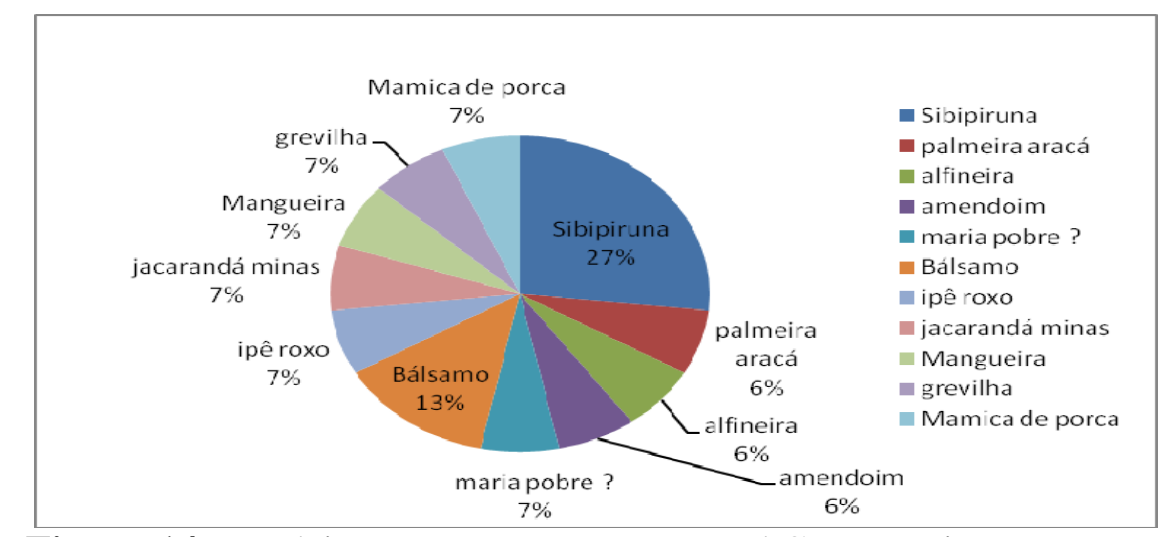

Figura 14: Espécies presentes na Praça José Costa Junior

Segundo Grey; Deneke (1978 apud MILANO; DALCIN, 2000), as espécies não devem ultrapassar 10-15\% do total de indivíduos da população arbórea. Nos resultados obtidos, muitas espécies estão acima destes 15\% citados e outras, sendo a grande maioria, ficaram abaixo dos $10 \%$, chegando até a 1\% do total de indivíduos.

Segundo Santamour Júnior (1990) apud Silva Filho (2005), a maior diversidade de espécies de árvores na paisagem urbana se faz necessária justamente para garantir o máximo de proteção contra pragas e doenças; dessa forma, segundo esse mesmo autor, recomenda-se não exceder mais que 10\% da mesma espécie, 20\% de algum gênero e 30\% de uma família botânica.

Como pode ser visto na tabela 2, em se tratando de podas, foram feitas podas em 3 praças e os indivíduos podados estavam com podas drásticas. 
Tabela 2: Lista das praças que tiveram podas.

\begin{tabular}{lcc}
\hline Praças & Sem podas & Podas drásticas \\
\hline Nestor Alves Ferreira & $56 \%$ & $44 \%$ \\
Flávio Cavalari & $93 \%$ & $5 \%$ \\
Praça dos Maçons & $45 \%$ & $55 \%$ \\
\hline
\end{tabular}

\section{CONCLUSÃO}

Concluiu-se que o maior problema encontrado foram as podas sem critério, o que prejudica a qualidade das áreas verdes (praças). Um segundo problema detectado é a baixa diversidade de espécies arbóreas.

\section{REFERÊNCIAS}

BIANCHI, C.G.; GRAZIANO, T.T. Caracterização e analise das áreas verdes urbanas de Jaboticabal - SP. In: HARDER, I. C. F. Inventário Quali-quantitativo da arborização e infraestrutura das praças de Vinhedo-SP. 2002. 122f. Dissertação (Mestrado em Fitotecnia). Escola Superior de Agricultura Luiz de Queiroz. Universidade de São Paulo. Piracicaba.

DEMATÊ, M. E.S.P. Princípios de paisagismo. In: HARDER, I.C.F. Inventário Qualiquantitativo da arborização e infra-estrutura das praças de Vinhedo-SP. 2002. 122f. Dissertação (Mestrado em Fitotecnia). Escola Superior de Agricultura Luiz de Queiroz. Universidade de São Paulo. Piracicaba.

DETZEL, V.A. Avaliação monetária de árvores urbanas. In: HARDER, I.C.F. Inventário Qualiquantitativo da arborização e infra-estrutura das praças de Vinhedo-SP. 2002. 122f. Dissertação (Mestrado em Fitotecnia). Escola Superior de Agricultura Luiz de Queiroz. Universidade de São Paulo. Piracicaba, 2002.

DETZEL, V.A. Arborização urbana: importância e avaliação econômica. In: HARDER, I.C.F. Inventário Quali-quantitativo da arborização e infra-estrutura das praças de Vinhedo-SP. 2002. 122f. Dissertação (Mestrado em Fitotecnia). Escola Superior de Agricultura Luiz de Queiroz. Universidade de São Paulo. Piracicaba.

ECKBO, G. O paisagismo nas grandes metrópoles. São José do Rio Preto: Instituto de Biociência, Letras e Ciências Exatas, 1981. 
GOOGLE EARTH. Europa technologies image: 2007 digital globe. 2007. Acesso em 9 dez. 2007.

GREY, G.W.; DENEKE, F.J. Urban florestry. In: HARDER, I.C.F. Inventário Qualiquantitativo da arborização e infra-estrutura das praças de Vinhedo-SP. 2002. 122f. Dissertação (Mestrado em Fitotecnia). Escola Superior de Agricultura Luiz de Queiroz. Universidade de São Paulo. Piracicaba.

GREY, G.W.; DENEKE, F. J. Urban florestry. In: MILANO, M.; DALCIN, E. Arborização de vias públicas. Rio de Janeiro: Light, 2000.

IGBE. Censo 2007. Disponível em: < http://www.ibge.gov.br/ > Acesso em: 29 out. 2007

LAPOIX, F. Cidades verdes e abertas. In: HARDER, I.C.F. Inventário Quali-quantitativo da arborização e infra-estrutura das praças de Vinhedo-SP. 2002. 122f. Dissertação (Mestrado em Fitotecnia). Escola Superior de Agricultura Luiz de Queiroz. Universidade de São Paulo. Piracicaba.

LORENZI, H. Árvores brasileiras: manual de identificação e cultivo de plantas arbóreas nativas do Brasil. v.1. Nova Odessa: Plantarum, 1992. 352p.

LORENZI, H. Árvores exóticas no Brasil: madeireiras, ornamentais e aromáticas. Nova Odessa: plantarum, 2003. 368p.

MARQUES, J.R. Meio ambiente urbano. In: BÁEZ CASCO, M.T.; SANTIAGO, A.G. Indicador de qualidade ambiental aplicado no centro de Florianópolis/SC. In: CONGRESSO BRASILEIRO DE ARBORIZAÇÃO URBANA, 5 a 8 nov. 2006, Maringá-PR. Anais... Maringá: Sociedade Brasileira de Arborização Urbana, 2006. CD-ROM.

MELLO FILHO, L.E. de. Vegetação e espaço urbano. In: HARDER, I.C.F. Inventário qualiquantitativo da arborização e infra-estrutura das praças de Vinhedo-SP. 2002. 122f. Dissertação (Mestrado em Fitotecnia). Escola Superior de Agricultura Luiz de Queiroz. Universidade de São Paulo. Piracicaba.

MILANO, M.S. Métodos de amostragem para avaliação de arborização de ruas. In: ROCHA, R.T.; LELES, P.S.S.; OLIVEIRA NETO, S.N. Arborização de vias públicas em Nova Iguaçu, RJ: o caso dos bairros rancho novo e centro. Revista arvore. Viçosa: Sociedade de Investigações Florestais, v.28, n.4, p.599-607, 2004.

MILANO, M.; DALCIN, E. Arborização de vias públicas. Rio de Janeiro: Light, 2000. 
PEREIRA, A.H.B.; BARRACHI, S.B.M. História e geografia de Ituverava. Ituverava: s.ed, 1997.

ROCHA, R.T.; LELES, P.S.S.; OLIVEIRA NETO, S.N. Arborização de vias públicas em Nova Iguaçu, RJ: o caso dos bairros rancho novo e centro. Revista Árvore. Viçosa: Sociedade de Investigações Florestais, v.28, n.4, p.599-607, 2004.

SANCHOTENE, M.C. Desenvolvimento e perspectivas da arborização urbana no Brasil. In: HARDER, I. C. F. Inventário quali-quantitativo da arborização e infra-estrutura das praças de Vinhedo-SP. 2002. 122f. Dissertação (Mestrado em Fitotecnia). Escola Superior de Agricultura Luiz de Queiroz. Universidade de São Paulo. Piracicaba.

SANTAMOUR JÚNIOR, F.S. Trees for urban planting: diversity uniformity, and common sense. In: SILVA FILHO, D. F.; BORTOLETO, S. Uso de indicadores de diversidade na definição de plano de manejo da arborização viária de águas de São Pedro-SP. Revista Árvore. Viçosa: Sociedade de Investigações Florestais, v.29, n.6, p.973-982, 2005.

SEITZ, R.A. A podas de árvores urbanas. In: CURSO EM TREINAMENTO SOBRE PODA EM ESPÉCIES ARBÓREAS FLORESTAIS E DE ARBORIZAÇÃO URBANA, 1, Piracicaba-SP, 30 e 31 out. e 1 nov. 1996. Cursos... Piracicaba, 1996. p.27.

SILVA FILHO, D.F.S.; BORTOLETO, S. Uso de indicadores de diversidade na definição de plano de manejo da arborização viária de águas de São Pedro-SP. Revista Árvore. Viçosa: Sociedade de Investigações Florestais, v.29, n.6, p.973-982, 2005.

VERAS, L.M.S.C. Plano de Arborização de cidades: metodologia. In: HARDER, I.C.F. Inventário quali-quantitativo da arborização e infra-estrutura das praças de Vinhedo-SP. 2002. 122f. Dissertação (Mestrado em Fitotecnia). Escola Superior de Agricultura Luiz de Queiroz. Universidade de São Paulo. Piracicaba. 